\title{
Prevalence of Plasmodium spp. in malaria asymptomatic African migrants assessed by nucleic acid sequence based amplification Marianna Marangi ${ }^{1}$, Rocco Di Tullio ${ }^{2}$, Pètra F Mens ${ }^{3}$, Domenico Martinelli ${ }^{4}$, Vincenzina Fazio 5 , Gioacchino Angarano², Henk DFH Schallig3, Annunziata Giangaspero ${ }^{1}$ and Gaetano Scotto*2
}

\begin{abstract}
Address: ${ }^{1}$ Dipartimento PrIME, Università di Foggia, Via Napoli 25, 71100 Foggia, Italy, ${ }^{2}$ Clinica delle Malattie Infettive, Ospedali Riuniti, Viale Luigi Pinto, 71100 Foggia, Italy, ${ }^{3}$ Royal Tropical Institute, Meibergdreef 39, 1105 AZ Amsterdam, The Netherlands, ${ }^{4}$ Dipartimento di Scienze Mediche e del Lavoro, Università di Foggia, Viale Luigi Pinto, 71100 Foggia, Italy and ${ }^{5}$ Laboratorio di Clinica Chimica, Ospedali Riuniti, Viale Luigi Pinto, 71100 Foggia, Italy

Email: Marianna Marangi - m.marangi@unifg.it; Rocco Di Tullio - rocditu@yahoo.it; Pètra F Mens - P.Mens@kit.nl; Domenico Martinelli - r.prato@igiene.uniba.it; Vincenzina Fazio - gaescot@gmail.com; Gioacchino Angarano - g.angarano@unifg.it; Henk DFH Schallig - H.Schallig@kit.nl; Annunziata Giangaspero - a.giangaspero@unifg.it; Gaetano Scotto* - g.scotto@unifg.it

* Corresponding author
\end{abstract}

Published: 12 January 2009

Malaria Journal 2009, 8:12 doi:10.1186/1475-2875-8-12
Received: 18 August 2008

Accepted: 12 January 2009

This article is available from: http://www.malariajournal.com/content/8/I/12

(c) 2009 Marangi et al; licensee BioMed Central Ltd.

This is an Open Access article distributed under the terms of the Creative Commons Attribution License (http://creativecommons.org/licenses/by/2.0), which permits unrestricted use, distribution, and reproduction in any medium, provided the original work is properly cited.

\begin{abstract}
Background: Malaria is one of the most important infectious diseases in the world. Although most cases are found distributed in the tropical regions of Africa, Asia, Central and South Americas, there is in Europe a significant increase in the number of imported cases in non-endemic countries, in particular due to the higher mobility in today's society.
\end{abstract}

Methods: The prevalence of a possible asymptomatic infection with Plasmodium species was assessed using Nucleic Acid Sequence Based Amplification (NASBA) assays on clinical samples collected from 195 study cases with no clinical signs related to malaria and coming from subSaharan African regions to Southern Italy. In addition, base-line demographic, clinical and socioeconomic information was collected from study participants who also underwent a full clinical examination.

Results: Sixty-two study subjects (31.8\%) were found positive for Plasmodium using a pan Plasmodium specific NASBA which can detect all four Plasmodium species causing human disease, based on the small subunit I8S rRNA gene (I8S NASBA). Twenty-four samples (38\%) of the 62 I8S NASBA positive study cases were found positive with a Pfs 25 mRNA NASBA, which is specific for the detection of gametocytes of Plasmodium falciparum. A statistically significant association was observed between I8S NASBA positivity and splenomegaly, hepatomegaly and leukopaenia and country of origin.

Conclusion: This study showed that a substantial proportion of people originating from malaria endemic countries harbor malaria parasites in their blood. If transmission conditions are available, they could potentially be a reservoir. Thefore, health authorities should pay special attention to the health of this potential risk group and aim to improve their health conditions. 


\section{Background}

Malaria is one of the most important infectious diseases in the world. The World Health Organization estimates that 300-500 million cases of malaria infections, with 1-3 million deaths globally occurring each year, of which 95\% is caused by Plasmodium falciparum [1]. Although most cases are found in the tropical regions of Africa, Asia, Central, and South America, there is a significant increase in the number of imported cases in Europe, in particular due to the higher mobility of people in today's society [2]. Approximately 7,000 cases of imported malaria are recorded in Europe annually [3]. Due to the misleading symptoms related to initial malaria (i.e. fever and other flu-like symptoms), prompt diagnosis and treatment are of great importance. The Centers for Disease Control and Prevention recommends that malaria should be considered in the differential diagnosis of febrile patients who have traveled to a region where malaria is endemic and in any patients who experience fevers of unknown origin regardless of their travel history [2].

The current standard for diagnosis is the microscopic examination of Giemsa-stained thick and thin blood smears [4-8]. This procedure is not expensive and in principle easy to perform, but becomes time-consuming in particular in cases of mixed infection or low parasitaemia and even with experienced microscopists examining the blood slides, misdiagnosis may occur [4,8]. To aid malaria diagnosis, other techniques have been developed, such as immunochromatographic assays based on Plasmodium antigen detection, but some of these tests perform poorly in cases of low parasitemia $[7,9,10]$ or, in contrast, lead to a false positive diagnosis of malaria due to the persistence of parasite antigen after adequate treatment $[7,11]$. Molecular detection for Plasmodium with PCR has resulted in increased sensitivity and species discrimination compared to either microscopic or immunochromatographic diagnosis of malaria [12-18]. PCR based assays are sensitive and can be converted to a quantitative format, if SYBR green or molecular probes (e.g. a Taqman probe or a molecular beacon) are used in real time format $[19,20]$. Alternatively, Nucleic Acid Sequence Based Amplification (NASBA) technology can be applied, which has as advantage above real-time PCR assays that it is fast to perform; i.e. 60 minutes for NASBA compared to up to four hours for real-time PCR [21,22]. NASBA assays, using molecular beacons as detection probes, has been developed for different Plasmodium species and has shown to be very sensitive with a detection limit of 20 parasites/ml blood $[22,23]$.

In the present study, NASBA using primers based on pan species Plasmodium-specific small sub-unit ribosomal RNA gene sequences [24] was used to evaluate the prevalence of Plasmodium species in a population of migrants.
Furthermore, a gametocyte specific NASBA based on the detection of the mRNA encoding for the $P$. falciparum gametocyte specific Pfs25 gene [25] was employed to detect mature sexual transmission stages in the same study population.

\section{Methods \\ Patient enrolment, information and sample collection, microscopy}

One hundred and ninety five blood samples were collected during the period April-September 2007 from study cases who were temporarily guests in a refugee camp managed by the Italian Red Cross, located in Borgo Mezzanone (province of Foggia, Italy). All guests were orally informed about the purpose of the study and invited to participate. Subsequent recruitment was on voluntary basis with no special inclusion criteria.

The study was reviewed and approved by the local Chief of the Red Cross and written informed consent was obtained from each study subject who was enrolled in the study. All study procedures were in agreement with the Helsinki Declaration (Edinburgh 2000). At enrolment, all study participants were interviewed using a questionnaire to obtain baseline demographic, clinical, and socioeconomic information and to assess their previous exposure to malaria. All enrolled subjects also received a full clinical examination and were treated accordingly.

\section{Anamnestic data}

The mean age of the enrolled study subjects $(n=195)$ was $25.1 \pm 5.7$ years (range: $16-40$ years) and the majority of them $(163,83.6 \%)$ were men. Potential female study candidates could often not be recruited for the study because they refused to undergo clinical examination. All enrolled study participants came from in total 18 sub-Saharan African countries (54.3\% came from East Africa, 35.9\% from West Africa, 10.8\% from Central Africa - Table 1) and they were in Italy for a mean period of 54 days (range: 19121 days).

Participants were allocated into three groups on basis of their reply to the questionnaire whether or not they had malaria in the past. Those people acknowledging one or more episodes of previous malaria in their country of origin were placed in group A: 58/195 (29.7\%); subjects who said that they did not previously had malaria were placed in group B: 93/195 (47.7\%); and individuals who could not remember a previous malaria infection were group $C$ : $44 / 195$ (22.6\%).

EDTA-anticoagulated blood samples were labeled and temporarily stored for a maximum of 24 hours in a freezer bag before transportation to the laboratory, where the samples were stored $\mathrm{a}-80^{\circ} \mathrm{C}$ until processing for nucleic 
Table I: Summary of country of origin, number of cases included, I8S NASBA positive cases and gametocyte carriers

\begin{tabular}{|c|c|c|c|}
\hline Country & $\begin{array}{c}\text { Total number of cases included in } \\
\text { the study }\end{array}$ & $\begin{array}{l}\text { Total number of I8S NASBA positive } \\
\text { cases from the respective country }\end{array}$ & $\begin{array}{c}\text { Gametocyte carriers as assessed by } \\
\text { Pfs } 25 \text { NASBA }\end{array}$ \\
\hline Ivory Coast - West Africa & 14 & 3 & 1 \\
\hline Togo - West Africa & 3 & & \\
\hline Guinea - West Africa & 8 & 2 & \\
\hline Somalia - East Africa & 37 & II & 1 \\
\hline Ethiopia - East Africa & 1 & & \\
\hline Eritrea - East Africa & 63 & 18 & 2 \\
\hline Ghana - West Africa & 20 & 6 & 3 \\
\hline Nigeria - Central Africa & 17 & 8 & 1 \\
\hline Burkina Faso - West Africa & 7 & 1 & 1 \\
\hline Mali - West Africa & 9 & 6 & 3 \\
\hline Cameroon - Central Africa & 1 & & \\
\hline Liberia - West Africa & 3 & 2 & 1 \\
\hline Gambia - West Africa & 4 & 1 & \\
\hline Chad - Central Africa & 2 & & \\
\hline Senegal - West Africa & 2 & I & \\
\hline Sudan - East Africa & 3 & 2 & \\
\hline Congo - Central Africa & I & 1 & \\
\hline Total & 195 & 62 & 13 \\
\hline
\end{tabular}

acids isolation. Thin and thick blood smears were prepared at the time of blood collection and stained with 10\% Giemsa stain ( $\mathrm{pH} 7.2$ ).

\section{Molecular analysis of blood samples}

\section{Nucleic acid extraction}

Blood samples $(100 \mu \mathrm{l})$ were mixed with $900 \mu \mathrm{l}$ of guanidium isothiocyanate lysis buffer before DNA and RNA isolation [26]. Thirty $\mu \mathrm{l}$ of silica dioxide was added to each sample after thorough mixing of the extraction mixture. Subsequently, nucleic acids bound to silica were washed twice with wash buffer (10 M GuSCN, $100 \mathrm{mM}$ Tris-HCL pH6.4), twice with 70\% ethanol, and once with acetone. Next, nucleic acids were eluted from the silica with $100 \mu \mathrm{l}$ water and stored at $-20^{\circ} \mathrm{C}$.

\section{I8S NASBA}

Pan-Plasmodium specific NASBA targeting 18S rRNA [GenBank accession number M19172.1] of Plasmodium falciparum, Plasmodium vivax, Plasmodium malariae and Plasmodium ovale was performed on an IQ5 Real-Time analyzer (Bio-RAD) [23]. Amplification reactions were performed using Nuclisens Basic Kit (bioMèrieux) following the manufacturer's manual at a $\mathrm{KCl}$ concentration of $80 \mathrm{mM}$. The reaction mixture $(5 \mu \mathrm{l})$ including primers and molecular beacon was incubated with the RNA extract $(2.5 \mu \mathrm{l})$ at $65^{\circ} \mathrm{C}$ for two minutes and subsequently at $41^{\circ} \mathrm{C}$ for two minutes. $2.5 \mu \mathrm{l}$ of Nuclisens enzyme mixture (AMV-RT, RNase $\mathrm{H}$ and T7 RNA polymerase) was added and amplification allowed for 90 minutes at $41^{\circ} \mathrm{C}$.
The forward primer was: 5' TCAGATACCGTCGTAATCTTA 3' (nucleotides 1066 to 1086 ); the reverse primer was: 5'AATTCTAATACGACTCACTATAGGGAGAAGGAACTT-

TCTCGCTTGCGCGAA-3' (T7 promoter sequence, linker and nucleotides 1216 to 1235 ); the Pf18S molecular beacon was: 5'-FAM- CGATCG-GAGAAATCAAAGTCTTTGGG-CGATCG-DABSYL-3' (molecular beacon stem of 6 paired nucleotides and nucleotides 1182 to 1201). Time to positivity (TTP), i.e. the time point during amplification at which the number of target amplicons detected became higher than the mean for two negative controls plus 20 standard deviations, was calculated. Standard ring stage parasite dilution series were used as positive controls. A sample containing only water and reactions mixture was used as negative control. The analysis of samples and appropriate positive and negative controls were performed in duplicate.

\section{Pfs25 NASBA}

$18 \mathrm{~S}$ rRNA NASBA positive samples were also analysed for gametocyte specific Pfs 25 mRNA QT-NASBA [25]. Briefly, real-time QT-NASBA for Pfs 25 mRNA [GenBank accession number AF193769.1] was performed on a NucliSens EasyQ analyzer (bioMèrieux) using the Nuclisens BasicKit for amplification according to the manufacturer's manual at a $\mathrm{KCl}$ concentration of $80 \mathrm{mM}$ and the same conditions of Real-Time 18S QT_NASBA.

The forward primer was 5'-GACTGTAAATAAACCATGTGGAGA-3' (nucleotides 204 to 227); the reverse primer was 5'-AATTCTAATACGA CTCACTATAGGGAGAAGGCATTTACCGTTACCACAAGTTA-3' (T7 promoter 
sequence, linker and nucleotides 338-359); the PfS25 molecular beacon was 5'-Texas-Red-CGATCG-CCCGTTTCATACGCTTGTAA-CGATCG-DABSYL-3' (molecular beacon stem of six paired nucleotides and nucleotides 259-278). Time to positivity was calculated, i.e. the time point during amplification at which the fluorescence detecting target amplicons exceeded the mean fluorescence of two negative controls plus 20 standard deviations. Standard gametocytes dilution series were used as positive controls. The samples and the positive controls were performed in duplicate.

\section{Statistical analysis}

In order to value the statistical association between history of malaria and signs and symptoms (i.e. splenomegaly, hepatomegaly, jaundice, urticaria, rales, leukopaenia, normocytic haemolytic anaemia, transaminase level) contingency double-entry tables were used and Odds Ratio and relative 95\% Confidence Intervals and $\mathrm{X}^{2}$ value were calculated. A p value of $<0.05$ was considered statistically significant.

In order to evaluate the statistical association between $18 \mathrm{~S}$ NASBA and the following variables: sex, regions of origin (West Africa, Central Africa, East Africa), previous episodes of clinical malaria as well as current clinical signs (i.e. splenomegaly, hepatomegaly, jaundice, urticaria, rales, leukopaenia, normocytic haemolytic anaemia, transaminase level) contingency double-entry tables were used and Odds Ratio and relative 95\% Confidence Intervals and $\mathrm{X}^{2}$ value were calculated. The t-Student's method was employed for the comparative evaluation of quantitative variables (continuous variables- i.e: age). A p value of $<0.05$ was considered statistically significant. In order to value the potential confounding effect of considered variables (sex, age, regions of origins, history of malaria, current clinical symptoms and signs) on $18 \mathrm{~S}$ NASBA positivity logistic regression model was performed.

\section{Results}

\section{Clinical features}

All examined study cases did not present at the time of examination or in the previous two months, the malaria paroxysm- characterized by high fever, chills and rigor. On physical examination 98/195 (50.2\%) cases were found to have splenomegaly and tender hepatomegaly; $50 / 98$ (51.0\%) were in group A, 27/98 (27.6\%) in group $\mathrm{B}$ and $21 / 98(21.4 \%)$ in group C. Splenomegaly as well as hepatomegaly was significantly associated with group A (splenomegaly: OR 2.71, 95\%CI $=1.36-5.48 ; \chi^{2}=9.53, \mathrm{p}$ $<0.05$; hepatomegaly: $\mathrm{OR}=3.01,95 \% \mathrm{CI}=1.16-7.76 ; \chi^{2}$ $=6.8, \mathrm{p}<0.05)$. However, an inverse relationship was found between spenomegaly and group $\mathrm{B}(\mathrm{OR}=0.48$, $\left.95 \% \mathrm{CI}=0.26-0.89 ; \chi^{2}=6.28, \mathrm{p}<0.05\right)$.
Other physical findings that have been observed are: jaundice 25/195 (12.8\%), scleral icterus 61/195 (31.3\%), urticaria $37 / 195(19.9 \%)$. Auscultation of the chest revealed scattered rales in about $25 \%$ of subjects. Cardiac examination was generally normal except for tachycardia in about $10 \%$ of patients.

Some abnormalities in routine laboratory tests were found in some study participants. Normocytic haemolytic anaemia presented in 61/195 (31.3\%) of the cases; leukopaenia due to a decrease in granulocytes and lymphocytes was present in 96/195 (49.2\%) and these cases also presented with eosinophilia in the presence of urticaria. Leukopaenia was significant associated with group $\mathrm{A}(\mathrm{OR}=$ $\left.2.19,95 \% \mathrm{CI}=1.11-4.36 ; \chi^{2}=6.05, \mathrm{p}<0.05\right)$. Liver function tests revealed elevated transaminase levels in 32/195 (16.4\%) of the cases and a mild to moderate increase in bilirubin (mostly indirect) in 86/195 (44.1\%) of the study subjects; this variable resulted inversely associated with group C (OR 0.09, 95\%CI =0.002-50.56; $\chi^{2}=8.28, \mathrm{p}<$ $0.05)$.

Serological markers for HIV were found positive in $0.8 \%$ of the enrolled cases, for HIV/HBV in $0.4 \%$ of the study individuals, for HIV/HCV in $0.6 \%$ of the cases, for HBV in $9.7 \%$ of the subjects and for HCV in $1.1 \%$ of the cases. Luetic infection was present in $6.4 \%$ of examined study subjects.

\section{NASBA}

In total, 62 study participants (31.7\%) were found positive for the presence of Plasmodium nucleic acids as revealed with the applied NASBA technique. These cases were distributed as follows: $18 / 58$ (31.0\%) belong to Group A, 28/93 (30.1\%) belong to Group B and 16/44 (36.4\%) belong to Group C. The distribution according to country of origin is presented in Table 1.

Microscopy confirmed the positive NASBA results in 14 cases and these cases were distributed as follows: six belonged to Group A, six belonged to Group B and two belonged to Group C. Quantification of parasitaemia was not available.

Plasmodium falciparum was observed in 13 samples and one sample was identified as being $P$. ovale. Thirteen cases (21\%) of this Plasmodium $18 \mathrm{~S}$ rRNA positive population were also found positive with a Pfs 25 mRNA NASBA, which is specific for the detection of gametocytes of $P$. falciparum. Four cases positive for gametocytes were confirmed by microscopy.

No significant association ( $\mathrm{p}>0.05$ ) was found between $18 S$ NASBA positivity and sex, age, history of malaria and region of origins. 
A statistically significant association was found between 18 S NASBA positivity and splenomegaly $\left(\chi^{2}=89.97, \mathrm{p}<\right.$ $0.001)$, hepatomegaly $\left(\chi^{2}=79.54, \mathrm{p}<0.001\right)$ and leukopenia $\left(\chi^{2}=89.97, \mathrm{p}<0.001\right)$ : in all subjects who were found positive with the 18S NASBA, splenomegaly, hepatomegaly and leukopaenia were reported. The relative OR values were not computable. No other signs and symptoms was associated with 18 S NASBA positivity.

By logistic regression model, a significant association was found between $18 S$ NASBA and country of origin (p < $0.05)$. In particular, a high probability to be positive at $18 S$ NASBA was observed in people coming from West Africa (OR: 33.8; 95\%CI: 1.1-1085.5), Central Africa (OR: 56.7; 95\%CI: 1.2-2598.9) and East Africa (OR: 235.6; 95\%CI: 3.9-14290.9). By using the same regression model, a significant inverse association was found between increased transaminase levels and 18S NASBA positivity (OR: $0.14 ; 95 \% \mathrm{CI}: 0.03-0.64 ; \mathrm{p}<0.05$ ) so that people with increased transaminase levels had a lower probability to be positive at 18 S NASBA. By the model, no significant associations $(\mathrm{p}<0.05)$ were found between $18 \mathrm{~S}$ NASBA positivity and sex, age, history of malaria, other signs and symptoms (splenomegaly, hepatomegaly, jaundice, urticaria, rales, leukopaenia, normocytic haemolytic anaemia).

\section{Discussion}

In many countries, the increase in imported malaria cases from different countries is due to the increasing number of people traveling to and from endemic areas, without taking appropriate prophylaxis or immigration from low income countries $[27,28]$. In the case of returning nonimmune travelers, malaria infection is often very obvious with severe disease and sometimes fatal outcome. In contrast, people from disease endemic countries may have acquired semi-immunity, resulting in less serious to none manifestations of disease, as was also shown in Spain [28], and recently also in Italy [29]. However, a proportion of this population may develop disease over time due to weaning immunity and/or contribute to possible transmission. In general, people originating from malaria endemic countries may have sub-microscopic levels of parasitaemia, but may feel not ill at all or present typical features of malaria. This is also reflected in the present study. Although many study participants could not recall having had malaria in the past, when being interviewed, there was no difference between the levels of infection between these participants and those who could recall an episode of malaria. In a substantial proportion of the examined population low levels of Plasmodium parasites were found with the applied NASBA technology. Furthermore, clinical examination revealed a statistically significant association between splenomegaly and 18S NASBA positivity. Malarial splenomegaly is believed to be a con- sequence of an immunological dysfunction due to recurrent episodes of malaria $[30,31]$. It is generally considered that prolonged exposure to malarial parasites (5-10 years) is needed to develop splenomegaly, this response is based on a overproduction of polyclonal IgM antibodies, leading to accumulation of high molecular-weight immunocomplexes and complement consumption. Long-term purification of immunocomplexes induces progressive hyperplasia of the spleen $[32,33]$. Patients usually present hypersplenism, and may have anaemia, leukopaenia, thrombopaenia and even haemolytic crises, depending on the severity [34]. A significant inverse association was found between increased transaminase levels and 18S NASBA positivity; i.e. people with increased transaminase levels had a lower probability to be positive at $18 \mathrm{~S}$ NASBA. However, the high prevalence of patients with viral hepatitis infections observed in this study could also be the consequence of other diseases.

It was further noted in the present study that $21 \%$ of the Plasmodium 18 S rRNA positive population was also found positive with a Pfs 25 mRNA NASBA, which indicates that these cases harbour gametocytes and may thus contribute to possible malaria transmission, even if the number of gametocytes is very low.

In Italy, malaria was eradicated after a campaign launched in 1947 just at the end of World War II. The campaign was carried out by indoor treatment with DDT; houses, stables, shelters and all rural structures were treated into the mid-1950s and also later in some endemic regions, such as Sardinia. Due to the persistence of sporadic malaria cases in some areas $[35,36]$, the WHO declared Italy free of malaria only in 1970. In order to circumvent the potential reintroduction of malaria, a strict surveillance system was set up, which is still in place and governed by the Ministry of Health and the Istituto Superiore di Sanità (ISS, Rome, Italy), following WHO guidelines [37].

Over the last two decades, with the exception of one autochthonous case registered in 1997 in a rural area of the province of Grosseto (Tuscany), which was followed by four more cases (i.e. a cryptic case by P. falciparum in 2003 [38], two cases due to organ transplantation in 2004 [39] and a transfusional case in 2005, all cases of malaria have been imported [40-42]). Until to 1999 the number of imported cases of malaria arose constantly, while from 2002 to 2006 a decrease between $1 \%$ and $7 \%$ per year has been registered [37] in both immigrant (-9\%) and among Italian citizens $(-28 \%)$. Most of the cases registered from 2002-2006 were among people from Africa (88.4\%), and, in particular, from Nigeria $(26 \%)$, Ghana $(17 \%)$, Senegal $(17 \%)$, Costa d'Ivoire (12\%), and Burkina Faso $(6.7 \%)$. Furthermore, additional cases were reported in 2000 [43] and in 2002 [44] in Chinese immigrants who 
traveled to Italy via Africa. Plasmodium falciparum was confirmed to be the most prevalent species imported in southern Europe $[27,28,37]$; in Italy, this species is responsible for $89 \%$ of the infection, $P$. vivax for $7.7 \%, P$. ovale and $P$. malariae, $6 \%$ and $1.5 \%$, respectively [29,37]. In addition, mixed Plasmodium infections have also been reported in Italy, with $58 \%$ of all these cases reported from a single town, Verona [29].

The distribution and density of the three potential vectors of malaria in Italy (Anopheles labranchiae, Anopheles superpictus and Anopheles sacharovi) are also under strict surveillance by Istituto Superiore di Sanità (ISS). Anopheles labranchiae is present in several areas of Central and Southern Italy and in some regions (Tuscany, Calabria, Puglia, Sardinia and Sicily) high density have been registered [41]. The density of An. superpictus is lower and breeding sites are restricted to Calabria coasts and Sicily while although An. sacharovi has not registered since over 30 years, its presence in low density cannot be excluded in Apulia and northern Sardinia regions [37].

The combination of the presence of potential vectors and gametocyte carriers may pose a risk for re-introduction of malaria in the country. However, it should be noted that certain climatological and ecological prerequisites should probably be also met before the disease is really reintroduced [37].

\section{Conclusion}

This study showed that a substantial proportion of people originating from malaria endemic countries and not showing clinical signs of malaria harbor Plasmodium parasites in their blood (i.e. 32\% of positivity to Plasmodium spp., $21 \%$ of population harboring P. falciparum gametocytes). If transmission prerequisites (e.g. vector, susceptible population and climatological conditions) prevail they could potential be a reservoir. Therefore, health authorities should pay special attention to the health of this potential risk group and aim to improve their health conditions.

\section{Competing interests}

The authors declare that they have no competing interests.

\section{Authors' contributions}

MM was involved in the laboratory work (blood processing, microscopy and NASBA analysis testings). RDT was involved in the fieldwork (blood sample collection). DM was involved in statistical analysis. VF and GA were involved in clinical consultancy. PFM performed daily supervision, analysis and technical assistance of the NASBA assays and substantial revision of the manuscript. HDFHS, conception of the study, critical reading and revi- sion of the manuscript. AG and GS, scientific and financial coordinators of the project and writers of the paper.

\section{Acknowledgements}

The authors are grateful to Annamaria Sarcinelli and Giuliana Valleri (Red Cross, Foggia, Italy) for their kind collaboration. Furthermore, we would like to thank all the study participants for their willingness to participate in the present study.

\section{References}

I. WHO-CISID 2008-malaria [http://www.who.int/malaria]

2. Filler S, Causer LM, Newman RD, Barber AM, Roberts JM, MacArthur J, Parise ME, Steketee RW: Malaria surveillance-United States, 200 I. Morb Mortal Wkly Rep 200I, 52(5): I- I4.

3. Muentener P, Schlagenhauf $P$, Steffen R: Imported malaria (I 98595): trends and perspectives. Bull World Health Organ 1999, 77(7):560-566.

4. Hanscheid T: Current strategies to avoid misdiagnosis of malaria. Clin Microbiol Infect 2003, 9:497-504.

5. Kain KC, Harrington MA, Tennyson S, Keystone JS: Imported malaria: prospective analysis of problems in diagnosis and management. Clin Infect Dis 1998, 27:142-149.

6. Milne LM, Kyi MS, Chiodini PL, Warhurst DC: Accuracy of routine laboratory diagnosis of malaria in the United Kingdom. J Clin Pathol 1994, 47:740-742.

7. Moody A: Rapid diagnostic tests for malaria parasites. Clin Microbiol Rev 2002, I 5:66-78.

8. Payne D: Use and limitations of light microscopy for diagnosing malaria at the primary health care level. Bull World Health Organ 1988, 66:621-626.

9. Murray CK, Bell D, Gasser RA, Wongsrichanalai C: Rapid diagnostic testing for malaria. Trop Med Int Health 2003, 8:876-883.

10. Rubio JM, Buhigas I, Subirats M, Baquero M, Puente S, Benito A: Limited level of accuracy provided by available rapid diagnosis tests for malaria enhances the need for PCR-based reference laboratories. J Clin Microbiol 2001, 39:2736-2737.

II. Craig MH, Bredenkamp BL, Williams CH, Rossouw EJ, Kelly VJ, Kleinschmidt I, Martineau A, Henry GF: Field and laboratory comparative evaluation of ten rapid malaria diagnostic tests. Trans $R$ Soc Trop Med Hyg 2002, 96:258-265.

12. Alves FP, Durlacher RR, Menezes MJ, Krieger H, Silva LH, Camargo EP: High prevalence of asymptomatic Plasmodium vivax and Plasmodium falciparum infections in native Amazonian populations. Am J Trop Med Hyg 2002, 66:64l-648.

13. Brown AE, Kain KC, Pipithkul J, Webster HK: Demonstration by the polymerase chain reaction of mixed Plasmodium falciparum and $P$. vivax infections undetected by conventional microscopy. Trans R Soc Trop Med Hyg 1992, 86:609-6I 2.

14. Jerrard DA, Broder JS, Hanna JR, Colletti JE, Grundmann KA, Geroff AJ, Mattu A: Malaria: a rising incidence in the United States. J Emerg Med 2002, 23:23-33

15. Morassin B, Fabre R, Berry A, Magnaval JF: One year's experience with the polymerase chain reaction as a routine method for the diagnosis of imported malaria. Am J Trop Med Hyg 2002, 66:503-508.

16. Myjak P, Nahorski W, Pieniazek NJ, Pietkiewicz H: Usefulness of PCR for diagnosis of imported malaria in Poland. Eur J Clin Microbiol Infect Dis 2002, 21:215-218.

17. Patsoula E, Spanakos G, Sofianatou D, Parara M, Vakalis NC: A single-step, PCR-based method for the detection and differentiation of Plasmodium vivax and P. falciparum. Ann Trop Med Parasitol 2003, 97:15-2I.

18. Calderaro A, Gorrini C, Peruzzi S, Piccolo G, Dettori G, Chezzi C: An 8-years survey on the occurrence of imported malaria in a non endemic area by microscopy and molecular assay. Diagn Micr Infec Dis 2008, 61 :434-439.

19. Perandin F, Manca N, Calderaro A, Piccolo G, Galati L, Ricci L, Medici MC, Arcangeletti MC, Snounou G, Dettori G, Chezzi C: Development of a real-time PCR assay for detection of Plasmodium falciparum, Plasmodium vivax, and Plasmodium ovale for routine clinical diagnosis. J Clin Microbiol 2004, 42: I 214-I219.

20. Andrews L, Andersen RF, Webster D, Dunachie S, Walther RM, Bejon P, Hunt-Cooke A, Bergson G, Sanderson F, Hill AV, Gilbert SC: 
Quantitative real-time polymerase chain reaction for malaria diagnosis and its use in malaria vaccine clinical trials. Am J Trop Med Hyg 2005, 73:191-198.

21. Cools I, Uyttendale M, Haese D, Nelis E, Debevere JH: Development of a real-time NASBA assay for the detection of Campylobacter jejuni cells. J Microbiol Methods 2006, 66:313-20.

22. Schneider $P$, Wolters L, Schoone G, Schallig H, Sillekens $P$, Hermsen $R$, Sauerwein R: Real-time nucleic acid sequence-based amplification is more convenient than Real-Time PCR for quantification of Plasmodium falciparum. J Clin Microbiol 2005, 43:402-405.

23. Mens PF, Schoone GJ, Kager PA, Schallig HDFH: Detection and identification of human Plasmodium species with real-time quantitative nucleic acid sequence-based amplification. Malaria J 2006, 5:80.

24. Schoone GJ, Oskam L, Kroon NCM, Schallig HDFH, Omar SA: Detection and quantification of Plasmodium falciparum in blood samples using quantitative nucleic acid sequence based amplification. J Clin Microbiol 2000, 38:4072-4075.

25. Schneider P, Schoone G, Schallig H, Vergage D, Telgt D, Eling W, Sauerwein R: Quantification of Plasmodium falciparum gametocytes in differential stages of development by quantitative nucleic acid sequence-based amplification. Mol Biochem Parasitol 2004, 137:35-41.

26. Boom R, Sol CJ, Salimans MM, Jansen CL, Wertheim-van Dillen PM, Noorda J Van den: Rapid and simple method for purification of nucleic acids. J Clin Microbiol 1990, 28:495-503.

27. Millet JP, Garcia de Olalla P, Carrillo-Santisteve P, Gascón J, Treviño B, Muñoz J, Gómez I, Prat J, Cabezos J, González Cordón A, Caylà JA: Imported malaria in a cosmopolitan European city: a mirror image of the world epidemiological situation. Malar J 2008, 8:7-56.

28. Salvadó E, Pinazo MJ, Muñoz J, Alonso D, Naniche D, Mayor A, Quintó L, Gascón J: Presentatión clínica y complicaciones de malaria importada por Plasmodium falciparum en dos groupos de pobalcion; viajero e immigrantes. Enferm Infect Microbiol Clin 2008, 26:282-284.

29. Mascarello M, Allegranzi B, Angheben A, Anselmi M, Concia E, Laganà S, Manzoli L, Marocco S, Monteiro G, Bisoffi Z: Imported malaria in adults and children: epidemiological and clinical characteristics of 380 consecutive cases observed in Verona, Italy. J Trav Med 2008, 15:229-236.

30. Corachan M, Cerralbo M: Syndrome da esplenomegalia tropical o esplenomegalia malarica hiperactiva. Med Clin 1986, 87:76-8I.

31. Ende J Van Den, Van Gompel A, Ende H Van Den, Taelman H: Hyperreactive malaria in expatriates returning from subsaharan Africa. Trop Med Int Health 2000, 5:607-6II.

32. Moraes MF, Soraes M, Arroz MJ, Do Rosario VE, De Graca JP, Abecasis $P$ : New concepts in hyperreacrive malarial splenomegaly. Acta Med Port 2003, 16:4|-46.

33. Puente S, Rubio JM, Subirats M, Lango M, Gonzales-Laboz J, Benito A: The use of PCR in the diagnosis of hyperreactive malarial splenomegaly (HMS). Am Trop Med Parasitol 2000, 94:559-563.

34. Crane GG: Hyperreactive malarious splenomegaly (Tropical splenomegaly syndrome). Parasitol Today 1986, 2:4-9.

35. Cefalù $M$, Gullotta $A$ : Su un episodio epidemico occorso in fase di eradicazione della malaria in Sicilia. Rivista di Malariologia 1959, 38:45-70.

36. Lazzara A, Morante $V$, Priolo A: Microfocolaio residuo di infezione malarica in provincia di Palermo. Ann Sanità Pubblica 1967, 28:725-4I.

37. Boccolini D, Romi R, D'Amato S, Pompa MG, Majori G: Sorveglianza della malaria in Italia e analisi della casistica del quinquennio 2002-2006. Giornale It Med Trop 2007, I 2: I-4.

38. Zamparo E, Airini B, Cicchirillo C: Un caso di malaria criptica a Pordenone. Giornale It Med Trop 2005, 10:139.

39. Menichetti F, Bindi ML, Tascini C, Urbani L, Biancofiore G, Doria R, Esposito M, Mozzo R, Catalano G, Filipponi F: Fever mental impairment, acute anemia, and renal failure in patient undergoing orthotopic liver transplantation: post-transplantation malaria. Liver Transplantation 2006, 12:674-676.

40. Sabatinelli G, Majori G: Malaria surveillance in Italy: | $986-1996$ analysis and 1997 provisional data. Euro Surveillance 1998, 3:38-40.
4I. Romi R, Boccolini D, Majori G: Malaria surveillance in Italy: 1997 analysis and 1998 provisional data. Euro Surveillance 1999, 4:85-87.

42. Romi R, Sabatinelli G, Majori G: Could malaria reappear in Italy? Emerg Infect Dis 2001, 7:915-919.

43. Matteelli A, Volonterio A, Gulletta M, Galimberti L, Maroccolo $S$, Gaiera G, Giani G, Rossi M, Dorigoni N, Bellina L, Orlando G, Bisoffi Z, Castelli F: Malaria in illegal Chinese immigrants, Italy. Emerg Infect Dis 200I, 7: 1055-1058.

44. Bisoffi Z, Matteelli A, Aquilini D, Guaraldi G, Magnani G, Orlando G, Gaiera G, Jelinek T, Behrens RH: Malaria clusters among illegal Chinese immigrants to Europe through Africa. Emerg Infect Dis 2003, 9: I 177-1 I78.
Publish with Bio Med Central and every scientist can read your work free of charge

"BioMed Central will be the most significant development for disseminating the results of biomedical research in our lifetime. "

Sir Paul Nurse, Cancer Research UK

Your research papers will be:

- available free of charge to the entire biomedical community

- peer reviewed and published immediately upon acceptance

- cited in PubMed and archived on PubMed Central

- yours - you keep the copyright 